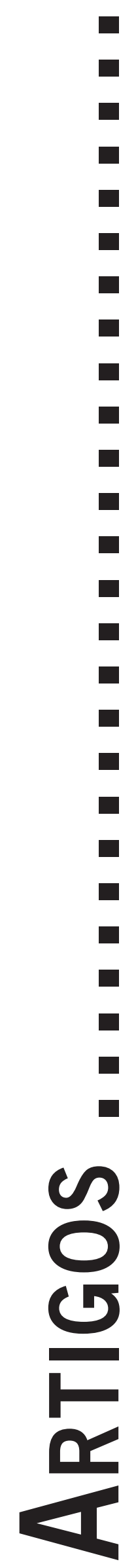




\title{
DA IMPORTÂNCIA DA TRAGÉDIA: O GÊNERO DRAMÁTICO E A FINITUDE HUMANA
}

\author{
On the Importance of Tragedy: the Genre Dramatic and Human Finity
}

La Importancia de la Tragédia: el Género Dramático y la Finitud Humana

Carlos Roger Sales da Ponte

Resumo: O caráter deste estudo teórico é realizar uma reflexão acerca da experienciação dos antigos helenos em relação às grandes Tragédias. Mostrar-se-á a Tragédia em suas dimensões como forma de poesia e de celebração, além de ser fonte perene de meditação do "sentido do trágico" da finitude humana.

Palavras-chave: Tragédia; "Sentido do Trágico"; Finitude.

\begin{abstract}
The character of this theoretical study is to realize a reflection concerning the experiencing of the old greeks in relation to the great Tragedies. To show Tragedy in its dimensions to it as form of poetry and celebration, beyond being perennial source of meditation of the "sense of tragic" of the finity the human being.

Keywords: Tragedy; "Sense of the Tragic"; Finity.

Resumen: La calidad de este estudio teórico es lograr un reflexion con respecto a el experienciacion de los viejos Hellenos en relación con las fenomenales Tragedias. La Tragedia será mostrada en sus dimensiones como forma de poesía y de la celebración, además de ser la eterna fuente de la meditación del "sentido del trágico" de la finitud humana.

Palabras-clave: Tragedia; "Sentido del Tragico"; Finitud.
\end{abstract}

A Tragédia helênica, tal como a conhecemos como gênero dramático, teve seu momento único e áureo, sem sombra de dúvida, na Grécia Clássica do século V até meados do século IV a.C. onde sua função principal não era de um "lazer" para os helenos, mas onde os cidadãos - durante as Grandes Dionisíacas (as festas anuais dedicadas ao deus Dioniso) - podiam vislumbrar o seu próprio modo de ser humano submetido aos desígnios dos deuses que conduziam de modo obscuro o curso de suas vidas e da pólis. Era algo que comportava um matiz religioso, mas também político e que relatava a necessidade de coesão social para manter a força da Polis.

Mesmo comportando uma função de amálgama destas dimensões, esta finalidade da Tragédia também comporta um quê de tarefa ingrata: como ela podia pretender reunir os cidadãos (enquanto Polis) a fim de exercerem o seu poder e seu lógos sobre suas existências, se o poder dos Olímpicos, por meio da Moira (o destino inevitável) prescrevia o fardo de todos? Lembrem-se das destinações dos heróis da na Ilíada.

As histórias de si mesmos fabuladas pelos poetas trágicos e as quais eram representadas pelos atores em cena, ao cantarem o drama, iluminavam a crença dos gregos como sabidamente e certamente superiores a outros povos porque possuíam um discernimento a respeito de sua existência no mundo. Isto é, consideravam-se "melhores" (aristói). Tal discernimento é algo que põe em curso um pensar sobre a purgação ali evocada nas arquibancadas do anfiteatro dedicado a Dioniso ${ }^{1}$.

A separação das dimensões política, social e religioso não podia fazer sentido para aquele povo, uma vez que esta espécie de divisão só surgiria na modernidade e definitivamente ancorada na contemporaneidade, criando uma compartimentalização do pensar, firmando-se como insuperável, uma vez que está arraigada na nossa linguagem/pensamento, fruto desse descompasso. Se a linguagem já é, por si só, universal e, ao mesmo tempo, manca em suas possibilidades de tudo querer-dizer, na nossa atualidade suas muletas deram lugar a uma "cadeira de rodas quadradas": hoje é muito mais difícil o dizer/pensar com a primordial fluidez dos antigos.

Tudo o que importava aos antigos helenos era, por meio de seus mitos repassados pela tradição oral desde os aedos, o educar-se por meio desta narratividade dialo-

\footnotetext{
O sentido dado a discernimento está lastrado no pensamento do filósofo alemão Hans-Georg Gadamer (2003, p. 466) para quem o momento do discernir é o dar-se conta de um lugar onde sempre se esteve e que até então uma espécie de cegueira havia impedido este estar cônscio. A saída da escuridão para a luz, isto é, para o sofrer da verdade como verdadeira experiência que se realiza, é o momento de autoconhecimento e, mais ainda, de uma autocompreensão como determinação possível do humano. Analogamente, não é esta uma das funções da clínica psicológica: um sofrer que pede a reestruturação significativa do "eu”, das vivências, as quais realizam um novo conhecer e compreender a si mesmo para além de onde se está?
} 
gada do drama a fim de receberem/refletirem "os valores e regras fundamentais da sociabilidade. Eis porque, intimamente ligados aos mitos, são a própria manifestação da vida pública que, por sua vez, fornece o fundamento às instituições da cidade" (Rosenfield, 2002, p.09). Enfim, o governo e as contradições do humano vislumbravamse nos dramas que, repito, nada tinham de lazer individual ou familiar, nem com caráter de "liturgia", sequer "cerimônia religiosa" como a entendemos. O governar, o humano, e a vida social possível eram contemplados por todos na Tragédia (Rosenfield, 2002, p.09). No período clássico, era desta forma que eles se entendiam.

Seguindo Aristóteles (1979), na sua Poética, longe de me sentir desolado ou com temor ${ }^{2}$, precisando ser purificado destas, a perplexidade é a afecção aqui em jogo, obrigando ao diálogo. Na verdade, o mote aqui são os valores cívicos em jogo na Atenas clássica e o mito que se encontra no cerne de toda Tragédia e de todo caráter trágico. Há algo de mitológico na vida de todo dia. Lembrem-se, por exemplo, das figuras bastante similares de Hermes e Cristo: a um só tempo eles são mensagem/mensageiro de um sentido a ser interpretado pelo humano.

O entendimento possível entre os helenos realiza-se pelo experienciar daqueles valores que incluem, em si mesmos, a dimensão política. Bem entendido, no sentido da Polis com seu éthos todo particular ${ }^{3}$. Sem este horizonte é impossível manter a Polis enquanto morada para o cidadão que o confirma enquanto tal. E este confirma a existência da Polis e sua necessidade. A imbricação íntima entre cidadão e Polis, difícil para nós hoje de ser compreendida, posto que dividimos a esfera pública e privada, é o pano de fundo das relações entre os helenos antigos. Um só fazia sentido pela existência do outro.

Quanto ao mito, além dele fazer parte do éthos da Polis como configuração da dimensão religiosa, confirma também o político e o cívico juntamente com a civilidade, isto é, o convívio mais ou menos suportável entre os cidadãos. A Tragédia mexia com estas dimensões. Esta união íntima é o mythos sendo logicizado pelo humano em interação dialogal: os helenos aprenderam, pela assistência ao drama trágico, como o desenrolar da existência pode vir a ser igualmente trágico se não se usa do diálogo deliberativo que põe o pensamento em movimento a fim de que, se possível, o humano não seja tomado por uma hýbris (desmesura), levando-o à hamartía (o erro), maculando a comunidade, necessitando, então, ser limpa por uma Kátharsis (purificação) ${ }^{4}$.

Esse "feixe de significações" também configuram a Tragédia, inclusive, como festa. Embora não fosse um

\footnotetext{
2 "Desolado" e "temor" são os termos usados por Aristóteles na Poética quando tece suas considerações sobre a Tragédia.

3 Além de possuir o significado de morada, Gazolla (2001, p.64) define Éthos como um "conjunto de valores, normas e instituições seguidas pelos homens em conjunto e configuram os modos de relações mútuas para a sobrevivência".

4 Este "feixe de significações está sempre onde o herói está e é sempre vivenciado pelos assistentes como forma de aprenderem sobre si mesmos e sobre a própria comunidade" (Gazolla, 2001, p. 31s).
}

espetáculo de diversão frívola, o seu sentido festivo volta sempre de novo com modos diferentes de representar, colocando mais uma vez o humano no caminho rumo à saída, ainda que parcialmente, da obscuridade para onde sempre retorna, educando-o na ponderação, equilíbrio e sobriedade, mesmo em seu modo de ser finito.

Mas se é uma procura de uma verdade possível da finitude do humano na tessitura de um sentido-que-faça-sentido, não é exatamente aí que entram as Tragédias áticas como suscetíveis de solicitar ao humano um pensar/dizer do seu existir? Não seria o momento propício do retorno deste pensar/dizer que aperreia o humano, constituindo o que foi chamado de festa? (Gadamer, 2003, p.180).

A festa presentifica-se, qual a experiência temporal da arte, também como celebração. Mas este celebrar não significa simplesmente uma festa que vai e volta, e quando volta, o faz de modo totalmente diverso. Não está em questão a diversidade que a festa pode possuir como uma de suas faces possíveis. O modo de ser da celebração festiva está no seu retornar como um devir, possível de compreendê-lo na medida em que retorna como diferente. E nada disso tem a ver com o tempo enquanto sucessão, mas de uma temporalidade da festa que só existe enquanto é celebrada e que ganha o ar de celebração porque nos toca de algum modo enquanto vem da tradição reeditada no re-dizer/re-pensar (Gadamer, 2003, p.181).

O espetáculo dramático da Tragédia só ganha seu sentido profícuo porque existe o espectador, o qual só se efetiva não porque senta-se nas arquibancadas do anfiteatro, mas como assistência, isto é, como participação naquilo que se deu e conhece realmente aquilo que se deu em seu conjunto. Quem assim participa, está em condições de poder experienciar o ser da obra de arte que não é mera teorização. Quem "teoriza" pretende erigir um edifício idealizado de um modo de ver o mundo e, portanto, explicá-lo. Este modo de se comportar próprio de um cientista é secundário e tardio em relação ao primordial deixar-se levar pela celebração, deixando-se levar pelo ato festivo. Não é um ato pessoal de uma vontade livre, mas um deixar-se sofrer pelas consequências da celebração que envolve o humano que olha, é atraído e dominado pelo que vê (Gadamer, 2003, p.181). O espectador está entregue à visão: como se estivesse fora-de-si, não como um delírio, mas se experienciando na entrega. $\mathrm{O}$ jogo dialogal e dialético com a festa oferece ao espectador a consciência experiencial de um modo de ser que contém uma dupla natureza: "esquecimento de si mesmo" e o "estar inteiramente em outra coisa". Enfim, uma presentificação do espectador na festa, como mais um que a celebra e, concomitante, se celebra na festividade (Gadamer, 2003, p.183).

Retornando ao contexto helênico, a Tragédia, enquanto festa/ritual cívico-político-religioso, provavelmente nunca foi tão importante para os helenos (mais ainda para os atenienses) como quando se viram em guerra contra seus próprios irmãos da Liga do Peloponeso, encabeçados por Esparta. Fico a imaginar, não um sentimento dúbio 
de patriotismo (semelhante ao que aconteceu na modernidade com seus nacionalismos apequenados) no qual eles lamentariam tal fato pensando que "irmãos de sangue e cultura não deveriam lutar”. Contudo, penso que os helenos já começavam a duvidar da capacidade de poder se entender. Os valores que valiam eram os do éthos da Polis. Os cidadãos já não conseguiam entrar em acordo tão facilmente durante as assembléias. Os tempos de uma unidade política suficientemente forte parecem afastarse. A perda de autonomia perante Esparta, vencedora da longa Guerra do Peloponeso, é o início de um lento e agonizante declínio. É partindo deste contexto que poderia explicar porque Aristófanes, o grande comediógrafo, na peça As Rãs, escolhe Ésquilo em vez de Eurípedes para voltar ao mundo dos humanos e fazer valer os antigos valores de uma Atenas de antigamente onde todos contribuíam para o bem da cidade. Uma Atenas antes de ser derrotada (Zilberman, 2001).

É nesse momento que Zilberman (2001) dá a entender que, não se entendendo mais, os helenos não conseguiam mais rever os antigos valores no fulgor de outrora. Os mitos ainda eram o cerne primordial e inspirador dos poetas em suas Tragédias, mas o direcionamento dado pelo poeta trágico já não anunciavam os mitos de modo a rever os éthos original e necessário à Polis e aos seus cidadãos. Estes pareciam estar, paulatinamente, esquecendo dos deuses e de suas raízes. Que tipo de cidadão seria esse sem a Polis a lhe ajudar a construir um sentido de existência?! Pergunta perturbadora para o heleno antigo, exemplificado por Aristófanes, apavorado com tal perspectiva.

A escolha de Aristófanes por Ésquilo parece compreensível. $\mathrm{O}$ antigo poeta inclinava-se mais para uma teomorfização do trágico do que para uma espécie de antropomorfização, que seria a característica de Eurípedes. Em Ésquilo há uma luta perene entre o Olimpo e o Hades. A Moira é quem manda no caminho humano e nada pode ser feito quanto ao seu poder. Por isso, para exercer a hýbris, os heróis do poeta nascido em Elêusis assemelhavam-se mais a deuses do que a humanos. Os humanos de verdade, aqueles que assistiam à suas peças, húmus que são, devem baixar a cabeça e se rebaixar perante os deuses. Esta seria sua condição, nada surpreendente, humana; humilde. Por fim, e por isto, a religiosidade de Ésquilo se espraia em suas peças (Brandão, 2001).

Zilberman (2001), apoiada por Aristófanes e por Nietzsche, condena o teatro de Eurípedes, como o decadente poeta que degenerou a Tragédia, o qual, em suas Bacantes pinta um Dioniso mais digno de riso que aquele pintado por Aristófanes na comédia As Rãs. A razão está que, depois da morte de Penteu pelas mãos das bacantes, tomadas que estavam do êxtase ao deus, Tebas está entregue aos cultuadores de Dioniso sugerindo, é verdade, que a cidade já não teria (ou não tem mesmo) alguém que a dirija. Pelo menos os versos finais do drama deixam entrever uma sorte não lá muito boa para Tebas, uma vez que Cadmo já está idoso e, agora, sem filhos.
Teme-se pelo pior uma vez que Dioniso não poupa ninguém, nem mesmo aqueles que o celebravam (Eurípedes, 2002). Fico a pensar o que seria, para uma cidade e para os cidadãos desta, não possuir a assistência de um deus e, pior, ser alvo de seu "divino desagrado" nada agradável. Segundo Zilberman (2001, p.59), "Eurípedes recria o mito, para destruí-lo, revelando sua descrença na religião, bem como nos valores fundantes da tragédia”.

Após aquela acusação de Zilberman (2001), que confirma a opinião de Nietzsche sobre o poeta de Salamina, eis que a autora surpreende ao afirmar que este mesmo poeta "encena o seu fim" e deixa claro mais ainda que, mesmo aí (não concordando com a sua poesia), Eurípedes mostra aquilo que deixará o gênero vivo para a posteridade mesmo depois de finda a Grécia, primeiramente nas mãos de Filipe da Macedônia e, depois, pelas primeiras conquistas militares da cada vez mais ascendente República Romana. E mesmo Aristófanes declarou que a Tragédia de Eurípedes morreria com ele. Errou duplamente: tanto o gênero como a obra do poeta permaneceram.

É fácil imputar a Eurípedes a alcunha de ateu, o que soa um tanto estranho para um heleno. Todavia, e segundo Zilberman (2001), os próprios helenos trataram de se entender de outro modo, mesmo quando as instituições políticas, desde Sólon, estavam desabando. Os antigos vivenciavam os ciclos de vida e morte de Dioniso pelas festas ao deus: Tragédias e Comédias. Os helenos estavam a "redigir um necrológio esclarecedor" de que fala Zilberman (2001). E isto pode possuir um duplo sentido: o primeiro sentido diz respeito ao fim de um ciclo de celebrações onde a própria encenação trágica é falar de vida e morte: seriam como um repensar das posturas dos cidadãos que vivificam a comunidade ou a tornam impura por uma mancha advinda de uma hamartía, fruto da hýbris. O segundo sentido possível diz respeito à decadência, profetizada por Eurípedes nas Bacantes, da Polis ${ }^{5}$. Ainda demoraria tal derrocada, mas não tardaria ${ }^{6}$.

Um modo diferente de os helenos se entenderem foi, a partir da falência da Polis e sem algo de externo que fosse semelhante a ela, começar a se voltarem para si mesmos como fonte de deliberação e vontade. O éthos começou a se voltar para dentro. Aqui estão os primeiros passos para aquilo que se chamará, muito mais tarde, de interioridade psicológica como fonte da vontade e de deliberação de um "eu”, de uma "subjetividade". Mesmo aqui nos antigos pode-se notar o surgimento de algo "interior" que despon-

\footnotetext{
Esta leitura é minha. Ela tem base no citado final da peça quando Tebas está entregue a um estado de exaltação báquica que turva e impede o pensar articulado próprio dos cidadãos da Polis. Simplesmente estão todos entregues ao frenesi furioso e à loucura. Esta decadência no drama é a crítica a Polis que se tornou decadente por não poderem dialogar razoavelmente, perdidos que estavam os cidadãos em vencerem uns aos outros na disputas na Ágora, ávidos que estavam de poder.

6 As Bacantes foi encenada após a morte de Eurípides que ocorrera em 406 a.C. Ou seja, bem no final do século V a.C. As falanges macedônicas adentram na Grécia no século seguinte e, na Batalha de Queronéia, em 338 a.C. derrotaram os helenos já enfraquecidos política e militarmente.
} 
taria nas Tragédias de Eurípedes, mas isso é ponto ainda controverso. Outras expressões filosóficas posteriores a Aristóteles tais como o Epicurismo e, bem mais tarde, o Estoicismo romano, irão servir como solo próprio para a concepção de interioridade tão cara ao cristianismo de Santo Agostinho em diante ${ }^{7}$.

As disputas de poder entre si pelos helenos não deixa de ser uma espécie de hýbris: não usaram do seu lógos discursivo a fim de encontrar, digamos, a medida da vida feliz da Polis. Na verdade, já a tinham, mas o exercício não foi constante e a sua grandeza fizeram-nos esquecer sua natureza dúbia; contraditória. Des-natureza humana. Todavia, isso não é surpresa: expulsaram os filósofos, mataram a Sócrates, aprenderam com muita avidez e destreza os discursos ensinados pelos sofistas, perdendo-se lamentavelmente, então, nos próprios e tortos raciocínios.

Opinião diferente sobre As Bacantes e sobre Eurípedes é a de Gazolla (2001) para quem o Dioniso de Eurípedes é a mostra do excesso humano, sua hýbris, levado às últimas consequências. Na verdade, Penteu poderia ser visto como o verdadeiro protagonista desta trama. Tal pode ser sustentado pelo teor da peça onde, primeiramente, o próprio Dioniso é um dos personagens, coisa que poeta nenhum havia feito, pelo que se tem notícia. Colocar um deus como protagonista de um drama. Que isso significa? O delírio báquico está em jogo desde o início em todos os personagens centrais: Penteu, as bacantes e o estrangeiro (este último, na verdade, era Dioniso travestido de humano). Penteu já está delirando ao repudiar o culto ao deus, e tudo o que faz e diz, aparentemente em conformidade com a razão que só ele vê como "razoável”, na verdade não o é. Sua obstinação em negar o deus o expõe à sua própria hýbris a qual se manifesta cada vez mais, e expõe o quanto ele é frágil diante do poder do deus. O respeito ao deus bem como aos outros deuses está também em jogo aqui. Não ceder espaço à sacralidade na própria existência é adentrar na Hýbris. É necessária essa reverência ao sagrado que, para o heleno antigo, importava mais que tudo, uma vez que aquelas dimensões (cívica, religiosa e social) não estavam separadas em sua vivência. É interessante notar que Penteu não sofre conflitos em suas ações, decisões e pensamentos. Não estar em conflito é algo que não é propriamente humano, ente que, sendo um vir-aser, não pode pretender univocidade perene de suas ações, decisões e pensamentos como se tudo fosse perfeitamente claro, distinto e indubitável (Gazolla, 2001).

Em suma, para Gazolla (2001, p.106), "ter um bom daímon, é partilhar da divindade, apenas partilhar. $O$ homem é um ser cuja natureza dupla e intermediária permite aproximação ao sobre-humano e ao subumano". Pretender alçar-se aos deuses ou recair aquém da animalidade, qualquer destes extremos, é Hýbris na certa. Por fim, Gazolla (2001) lembra o mito de Epimeteu citado por Platão/Sócrates no Protágoras. Este deus que

\footnotetext{
Observações altamente pertinentes sobre esse assunto podem ser encontradas em Gazolla (2001).
}

sofre de esquecimento não se lembrou do humano na hora de distribuir qualidades a todos os seres animados. Sem atributos "naturais", o humano foi presenteado por Prometeu com uma parcela do divino: o fogo do deus artesão, Hefesto. Sendo, em parte, animal, sofre com essa condição. Mas como possui uma centelha do sagrado, se sobressai àqueles como artífice de si. Daí sua natureza contraditória e dúbia. E, mesmo assim, nada está garantido. É responsabilidade do humano gerir sua balança ontológica irresolvível.

O aspecto pedagógico fundamental ao grego da Polis está exatamente em buscar, pelo viés dialogal, pelo lógos que lhe é próprio ao pensar, a sophrosyne, o equilíbrio, tão caro a este povo. E o humano precisa sempre não esquecer que isto não possui resolução, sendo tarefa irremediavelmente recorrente durante todo o existir (Gazolla, 2001). A existência humana, assim assumida e vislumbrada, se configura como uma espécie de hermenêutica: é a tematização da experiência propriamente humana em que somente o modelo científico não serve como prisma para sua compreensão (temática que será recorrente nas psicologias existências-humanistas). Os helenos antigos já eram, ao seu modo, hermeneutas: como artistas, interpretavam a si mesmos.

Dito isso, pode-se perguntar: como ficou a Tragédia? Não houve outro grande poeta após Eurípedes. O “esclarecedor necrológio” estava completo. Mas o gênero continua vivo porque remete para nós mesmos enquanto possíveis parceiros dialogais que, como os helenos, em um determinado momento da história humana, souberam realizar o lógos em sua virtude máxima enquanto civilização, a qual jamais outra sequer chegou perto.

Ao nos debruçarmos sobre o sentido do trágico, Gazolla (2001) pode nos dar a mão nesta empreitada com mais uma indicação de diálogo com aquilo que a tradição helênica legou. Por que o drama ático dialoga conosco ainda hoje? O gênero foi-se há muito tempo. Que resta para nós? Resta a força interpretativa que nos perpassa como modo de ser linguagem, e com o qual e pelo qual constituímos este perecível mundo atravessado por um devir nem sempre claro, mas que é sempre clarividente penumbra do compreender e autocompreender. Nas palavras de Gazolla:

Por que nos falam tão de perto as tragédias? Porque há nelas o drama humano, demasiado humano, da existência; há o drama universal do homem envolto em suas afecções, na natureza, no sagrado e no profano, em seus limites e deslimites. Nietzsche adivinhou essa força e reconheceu-a como Dioniso atravessando a tragédia e desnudando o que há de eterno e ilogicizável no homem, um ser dividido, tensional, limitado, por isso mesmo frágil. Isso é o atemporal, aquilo que é sempre reconhecido. $\mathrm{O}$ que concerne à encenação teatral como ritual mítico, político e religioso. Nesse ponto, há um distanciamento que não se pode ultrapassar (Gazolla, 2001, p. 24s). 
Então, é assim que a Tragédia nos apela? Como um drama de fundo ontológico jamais resolvível? Como aquela relação com a sacralidade da existência própria aos antigos nos ressoa? Como, do alto Olimpo, o fogo devídico encandeia o humano em sua finitude?

O "efeito trágico" apontado por Gazolla (2001) é reiterado por Gadamer (2003) em suas reflexões sobre este mesmo modo de ser quando parte do humano a olhar o drama de fora para escutar o clangor do eco que ressoa em seu íntimo finito. É, repito, uma experiência e assim deve ser compreendida. Desde estas reflexões, o sentido do trágico poderá mostrar-se em seus contornos possíveis.

A fim de vislumbrar o comportamento de entrega à obra de arte em seu modo de ser, Aristóteles dá o ponto de partida em sua Poética. Logo, o jogo poético do trágico pode representar sua essência possível, sobretudo se se ativer ao fenômeno do trágico como sofrendo uma mediação dialogada por parte do espectador.

O efeito trágico visto como efeito em andamento já é um diálogo entabulado com o drama. Se não fosse assim, não teria im-pressionado ao espectador, sendo, portanto, não um assistente, mas alguém "de corpo presente", como se diz. E já que o espectador está aí implicado, o sentido do espetáculo trágico adquire sua processualidade. A experiência do trágico não é exterior como se fosse um conceito independente da experiência, mas processo representado por este jogo dramático (Gadamer, 2003).

O efeito trágico no espectador já é participação como parceria dialogal. Mas é um diálogo, a princípio, estranho. O que está em jogo é o ser-jogado do espectador na desolação e no temor. Gadamer (2003) afirma que a "representação atua através" destas afecções. Este "através" quer significar que o sentido do trágico não se encontra pronto quando o drama se encerra, mas se mostra em todo o seu desenrolar do começo ao fim, presentificado sempre.

Diante desta experiência, o espectador, se tiver um pouco de sensibilidade, não pode deixar de pensar em si mesmo como sendo e tendo uma existência que suscita desolação e temor. O existir está em aberto no tempo: não somos; mas devimos. As afecções dão-se pelo ocasional que é o dar-se conta da finitude que nos concerne. Ontologicamente, este divisão/devir impera em nosso âmago. É nosso furo ontológico. Negar a finitude, em qualquer de suas de suas faces, é pretender ocupar lugar supostamente divino. Por sua vez, a afirmação exagerada da finitude pode levar a um ceticismo improdutivo e à paralisia. Em nenhum destes casos é possível dialogar.

O desolador é a tristeza por estarmos determinados como abertura: é uma certa nostalgia não-se-sabe-de-quê uma vez que estar aberto é não se possuir nenhum tipo de certeza, mas buscar algo sobre o qual nos segurar.

E nos espantamos como temor: esse medo que não incita a fuga, mas torna o humano cuidadoso no desdobrar desta autocompreensão como ente aberto. Assim, Gadamer (2003) indica de um modo bem penetrante, a junção destas afecções (Phobos e Eleos) como ruína. Escreve ele que o espanto de tremor que se apossa de nós quando vemos alguém ir às pressas de encontro com a sua ruína, e tememos por este alguém. A desolação e o temor são formas de êxtase, do estar-fora-de-si, que atestam o fascínio daquilo que se desenrola diante de nós (Gadamer, 2003, p. 189).

Pelo exposto, não é que o humano busque a própria ruína pessoal, mas nós mesmos já sempre somos esta ruína que teima em restaurar-se pelo lidar com a finitude. Este contato denuncia que sempre tendemos a nos esquecer desta finitude que retorna sempre como um apelo para um novo restaurar. Afinal somos artífices.

A purificação, da qual falava Aristóteles, não é uma limpeza, tal como se joga o lixo fora, mas uma "melancolia trágica" que joga luzes na arrumação da casa. As afecções podem ser contrárias e mesmo contraditórias (dor/ prazer), advindas de um "alívio" e "solução", tornando-se, tão-somente, paradoxais. Nada mais humano.

No fundo de nossa autoconsciência romântica e ingenuamente esperançosa, gostaríamos que não fôssemos tão cheios de vazios, os quais, para nosso desespero, não se preenchem nunca. Gadamer (2003) aponta isto como uma divisão ontológica sempre nos lembrada pela experiência do trágico e, por esta mesma experiência, podemos nos reconciliar conosco mesmo. Seja na condição do espectador (o qual não é nunca mero espectador), seja na condição do herói trágico: ambos experienciam esse dividir/reconciliar como uma afirmação de si em termos de um retorno sempre retomado em direção a si mesmo. Nada mais dialético sem ser conceitual: dialética tensa e experiencial que lembra Kierkegaard.

Do que até agora foi dito, nada há aqui que possa estar relacionado à culpa. Tal afecção só diz respeito ao nosso solo próprio, histórico, em nada tem haver com a Tragédia. Por contraposição, Gadamer (2003) diz que não há dívidas a serem pagas no trágico. Logo, nem culpa pode haver por contrair alguma dívida. Pelo contrário, sempre existe o que ele chama de "resto": consequências das sucessivas experiências de nossa finitude que permanecem em nosso ser e que auxiliam a configurar a essência do trágico, lembrando-nos sempre.

A confirmação do trágico pelo espectador é uma comafirmação de si. Ele, o espectador, comunga com o herói, tendo como convincente que, aquilo que acontece com o herói, pode acontecer consigo: é o reconhecimento em si da finitude partilhada com o herói. A significação do trágico torna-se, assim, exemplar e pedagógica. A finitude é nossa "ordem metafísica do ser válida para todos".

Este furo ontológico pode mesmo ser melhor compreendido pela palavra destino. O termo "destino" pode suscitar tanto um conjunto de ocorrências preestabelecidas por Deus (mais conhecido como Providência Divina), ou um sei lá o quê místico. Um sentido mais produtivo de destino pode seu um caminho a ser percorrido. No latim, methodus. Mas que methodus? Este mesmo ente humano que "es- 
pecta” e "representa" a face-máscara da finitude (Gadamer, 2003). O humano é o caminho errante de si mesmo.

Nessa "comunhão do assistir" é que o trágico de nós mesmos se dá como re-presentado e re-conhecido. O estético de nós é uma estética da existência, para utilizar uma expressão de Foucault. O encontro com o trágico é, pois, um exercício do lógos (como diálogo) se efetivando no contato com as Tragédias. Não é um estar-de-fora da obra como pensava a estética iluminista que via a obra de arte como mero objeto exterior de contemplação de uma subjetividade independente. Na verdade, e mais ainda, põe-se como participação nesta tradição que nos chega com a figuração da saga de um herói que é a nossa própria saga. Deste modo, não é à toa a comoção em que nos enredamos diante desta tradição trágica: é a continuidade consigo mesmo aprofundando-se sempre. De todo modo, esta continuidade implica a descontinuidade também ontológica. Esta tensão paradoxal é mais um indicativo da finitude que somos.

Aristóteles (1979), na Poética, chegou a dizer que a poesia é mais filosófica que a história. Esta colocação é pertinente, pois a dialogicidade do artista é com o mundo do qual ele nunca está apartado. Por isso, afirma Gadamer (2003), não faz sentido as teses que falam de "criação artística” como alguma coisa livre e genial, partindo do nada. Ao contrário (e ainda com Aristóteles), o poeta é um praticante da mímesis. Um mímico. Ele partilha do mesmo horizonte de sentido do público que assiste sua arte. É a distância insuperável do ser que se pretende é representar. O trágico criado pelo poeta é, primeiramente, um diálogo de sua alma consigo mesma, parafraseando Platão no Sofista. Experienciou o poeta aquelas afecções de temor e desolação e, por isso, foi purificado, isto é, exacerbou-as. O espectador empreende diálogo semelhante. Entretanto, o mundo é o mesmo para ambos: um horizonte-lógos em aberto.

O poeta ama como Eros que une e re-une (no sentido grego) o que está separado, mesmo deixando exibir a particularidade daqueles que relacionam-se com o drama, perfazendo o seu sentido dialogado. A marca desta relação que une e re-une pode ser vislumbrada pela figura de uma cicatriz, marca indelével. A relação com o trágico onde os numes e heróis se enfrentam é uma relação que deixa cicatrizes em nós meros mortais, para não deixar de recordar que esta festa/celebração que tenta compreender humanos e divinos, se dá no tempo e como linguagem. Poesia, enfim! Como nos assevera Nietzsche (1992), "Em torno ao herói tudo se torna tragédia, em torno ao semideus, drama satírico; em torno a Deus tudo se torna - como? 'mundo', talvez?" (Além do Bem e do Mal, aforismo 150).

Paro aqui. Detenho-me arbitrariamente. Jogo-me neste horizonte-lógos existencial e, mesmo, fenomenológico do caráter de abertura da existência.

Postado nesta visão dramática e vivificante da tragédia e da vida, deixo um poema escrito por um colega, filósofo e poeta, Dalton Walbruni.
Dionisos não é lógico e nem um matemático! não se embriaga dentro de uma equação, não canta, não dança, não corre, nem brinca, dentro de uma raiz quadrada, porque Dionisos é a raiz da videira!

Dionisos é a vida nua! que corre e brinca, por entre as fibras da videira, quando excitado, transmuda-se em uvas, quando pisoteado, transforma-se em vinho, quando degustado, transmuda-se em música e dança!

Dionisos é flauta que toca o desejo! a faca que fere a videira, a taça que embriaga a vida!

\section{Referências}

Aristóteles (1979). Poética (Col. Os Pensadores). São Paulo: Abril Cultural.

Brandão, J. S. (2001). Teatro grego: tragédia e comédia. Petrópolis: Vozes.

Eurípedes (2002). Ifigênia em Áulis; As Fenícias; As Bacantes (M. da G. Cury, Trad.). Rio de Janeiro: Jorge Zahar Editor.

Gadamer, H-G. (2003). Verdade \& Método - I: traços para uma hermenêutica filosófica. Petrópolis: Vozes.

Gazolla, R. (2001). Para não ler ingenuamente uma tragédia grega: ensaio sobre aspectos do trágico. São Paulo: Loyola.

Nietzsche, F. (1992). Além do bem e do mal: prelúdio a uma filosofia do futuro. São Paulo: Companhia das Letras.

Rosenfield, K. H. (2002). Sófocles \& Antígona. Rio de Janeiro: Jorge Zahar Editor

Zilberman, R. (2001). Como os gregos se entendiam. Em K. Rosenfield (Org.), Filosofia \& literatura: o trágico (pp. 5759). Rio de Janeiro: Jorge Zahar Editor.

Carlos Roger Sales da Ponte - Psicólogo, Mestre em Filosofia e Mestre em Psicologia pela Universidade Federal do Ceará (UFC). É Professor Assistente do Curso de Psicologia da UFC (Campus Sobral) e Coordenador do VEREDAS - Círculo de Estudos em Fenomenologia, Existencialismo e Psicologia Humanista. Endereço Institucional: Curso de Psicologia da Universidade Federal do Ceará (Campus de Sobral). Av. Lúcia Sabóia, 215 - Centro. CEP 62010-830 - Sobral, CE. Email: jardimphilo@yahoo.com.br

Recebido em 12.04 .10 Primeira Decisão Editorial em 30.09 .10 Aceito em 18.10 .10 